\title{
Performance Evaluation and Simulation of Embedded WEB Server Based on ARM Platform
}

\author{
Xian Zhang, ${ }^{1,2}$, Dong Yin ${ }^{1,2, *}$, Yiwen Liu ${ }^{1,2}$ and Jia Liu ${ }^{1,2}$ \\ ${ }^{1}$ School of Computer Science and Engineering, Huaihua University, Huaihua 418008, Hunan, China \\ ${ }^{2}$ Key Laboratory of Intelligent Control Technology for Wuling-Mountain Ecological Agriculture in Hunan Province, Huaihua \\ 418008, Hunan, China \\ ${ }^{*}$ Corresponding author
}

\begin{abstract}
With the wide application of embedded devices and Internet of things equipment, embedded WEB server has become an indispensable part of its intelligent equipment. In order to select and build the embedded WEB server efficiently, this paper presents the performance simulation evaluation of three kinds of commonly embedded WEB server based on Boa, Tomcat and Apache (httpd). The embedded experimental platform based on ARM processor is set up to test the static and dynamic performance of Boa, Tomcat, Apache (httpd), such as connection rate, cpu utilization rate, throughput rate, click rate. The experimental results can provide a theoretical basis for the selection, construction and control of embedded WEB server based on ARM devices, which has important practical value.
\end{abstract}

Keywords-embedded web server; static performance; dynamic performance; ARM processor

\section{INTRODUCTION}

With the arrival of the Internet plus era, a new generation of information technology such as the Internet platform, the Internet of things technology, big data analysis and WEB service technology will be more and more integrated into the modern equipment products, modern enterprise and People's Daily social life. More and more Internet of things devices, embedded intelligent products emerge, such as Smart watches, smart base stations, smart medical devices[1].In order to effectively monitor and control the operation status information of these Smart devices, a large amount of data is need to collect and analyze. Embedded WEB server software can generate a huge amount of time series data during operation, such as Access log data, perform trajectory data, and system status information data etc. So the embedded WEB server running in these devices plays a critical role to provide and gather data. Usually embedded WEB server software need to run continuously for a long time and unattended, therefore, the performance of embedded WEB server software is particularly important and needs special attention and attention, especially for some of the Internet of things devices and smart products that need to work in the harsh outdoor environment. Therefore, how to improve and ensure the high performance and stability of the server - side software has become a thorny problem that many enterprises focus on. Generally speaking, the main reasons for the performance and exception of embedded WEB server software are the performance defects of WEB server software, the bottleneck of the hardware platform of the device etc[2,3]. Therefore it is only by testing and evaluating the performance problems of embedded WEB servers through the specified bembedded platform, after thorough analysis for the problem and find defects lead to corresponding problems, effectively improve the performance of the embedded WEB server software to essentially improve the performance of the Internet of things and embedded intelligent devices which to provide users with better service and user experience[4].

This article simulated and evaluated the main performance indexes of several mainstream embedded WEB servers such as Boa server, Tomcat server, Apache (HTTPD) server etc, which running on internet of things devices and embedded smart products base on the mainstream CPU hardware ARM platform.

\section{WEB SERVER PERFORMANCE INDICATORS}

The performance evaluation of embedded WEB server is to test the performance of embedded WEB servers to connect requests according to certain metrics in a specific software and hardware environment, and to test response speed, maximize the number of performance connection requests and other performance indicators. In the process of testing and analysis the server performance, need to use a variety of indicators to measure the performance of Web server system, and the performance metrics are main basis of the server performance measurement, modeling and analysis. The common performance metrics of the embedded WEB server evaluates has the server response time, system throughput, system CPU resource utilization, connection number of concurrent users, HTTP processing number, session number, network traffic etc[5]. The following will introduce the key indicators that relevant to this article.

\section{A. Timeing Indicators}

The current performance testing tools and performance models define the response time mostly from the end user perspective, referring to the time total from the client to the server sending a request to the response to receive the request[6]. The response time estimates are usually measured by seconds or milliseconds. The response time estimates are usually measured by seconds or milliseconds. The response time mainly includes page response time, server response time, transport round-trip time, TCP connection establishment time etc. Figure I shows the breakdown diagram of the page response time for the embedded WEB server. 


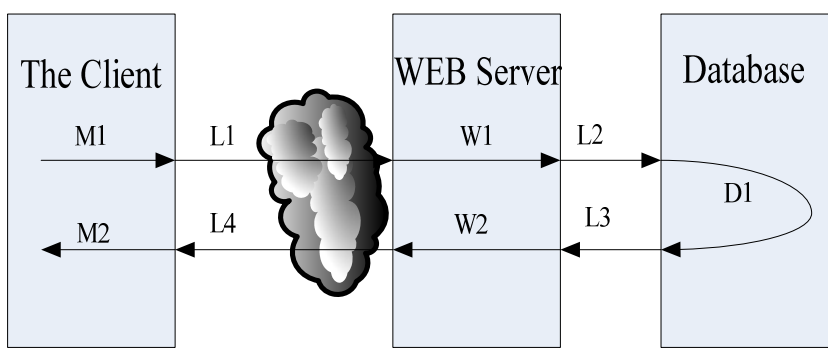

FIGURE I. THE BREAKDOWN DIAGRAM OF THE PAGE RESPONSE TIME FOR THE EMBEDDED WEB SERVER

It can be seen from the Figure above, the overall response time(waiting time) of web page $=(\mathrm{L} 1+\mathrm{L} 2+\mathrm{L} 3+\mathrm{L} 4)+(\mathrm{M} 1+$ $\mathrm{M} 2+\mathrm{D} 1+\mathrm{W} 1+\mathrm{W} 2)$, there are two types of main network latency and application processing wait time, network transport latency is the time that data is transmitted from one server to another, like (L1+L2+L3+L4); application processing latency refers to the time it takes to process the data business within the server, like (M1+ M2+D1+W1+W2). Now most of performance testing tools and performance test models refer to WEB server page response times as defined in the Figure above. But the page response times of the web server are not an isolated indicator, it must be closely related to the number of concurrent users, the system resource utilization, the network status, test configuration and other performance indicators, otherwise, it would be meaningless.

\section{B. System Capacity Indicators}

The capacity indicators of embedded WEB server system refers to the effective access that can be accommodated by the embedded WEB server under normal operation. It can include performance indicators such as concurrent user number, system throughput, connection speed and so on[7]. The number of concurrent connections refers to in a given period of time, can concurrently access the embedded WEB server and interact with the user. The number of concurrent connection number of users is an important reference index of the embedded WEB server system of service quality, with the increase in the number of concurrent connections to resources of embedded WEB server system using response the time ratio and the system will be changed. The throughput refer to the number of the request users that the embedded WEB server system can handle in a specific period of time, it is usually expressed in terms of requests per second. The throughput of the embedded WEB server systems often needs to be measured and analyzed at different stages, it throughout the cycle of system design, system development, and system release, such as, in the server system capability design phase, the system throughput is the key parameter to determine the hardware and system requirements of the embedded WEB server site. Moreover, the throughput of system plays a crucial role in identifying the performance bottleneck of embedded WEB server system and improving the performance of embedded WEB server system. So the system capacity index also needs comprehensive evaluation, so it can not be an isolated index.

\section{The Resource Uilization Indicators}

The utilization of system resources refers to the use of different resources of the embedded WEB server system (such as the CPU, memory, disk, network bandwidth, etc.) of the server[8].The resource utilization indicators of the embedded WEB server systems include CPU utilization, memory utilization, disk utilization, available network bandwidth and so on. General system resource utilization and system usually is proportional to the user load, but when the system load reaches a certain level, the system user growth does not significantly change the utilization rate of resources of embedded WEB server system, which can reach the maximum bearing system resources of the embedded WEB server system. In order to find the performance bottleneck of embedded WEB server system, it usually takes a long time to test the system performance to record the status of system resources, and check whether the performance of embedded WEB server system can be improved by changing the system resources.

\section{BUILD THE SimUlation PlatForm}

In this paper, the performance evaluation of the embedded WEB server is based on the internet of things smart devices and embedded smart products etc, however most of these smart devices are based on ARM processor cores currently, therefore the device based on ARM processor is used as the experimental platform in this article. Currently, the mainstream embedded WEB servers used in the embedded devices include Boa, Tomcat, Apache, Mathopd, Appweb, Goahead etc, in this paper, the performance simulation comparison is the mainstream embedded WEB servers that Boa, Tomcat, and Apache (HTTPD) is evaluated. Build the experimental platform that the performance evaluation of embedded WEB server, first, it need to cross-compile and migrate Boa, Tomcat, Apache (HTTPD) servers to ARM platform devices, and set the corresponding configuration file and parameters.

The test tool of the LoadRunner software is used for testing the performance of the embedded WEB server, the LoadRunner software is installed on the client. The embedded WEB server running on the remote intelligent device, by running LoadRunne testing software on the client to simulate concurrent user load to test the remote embedded WEB server performance. Figure II shows the test platform structure of the embedded WEB server.

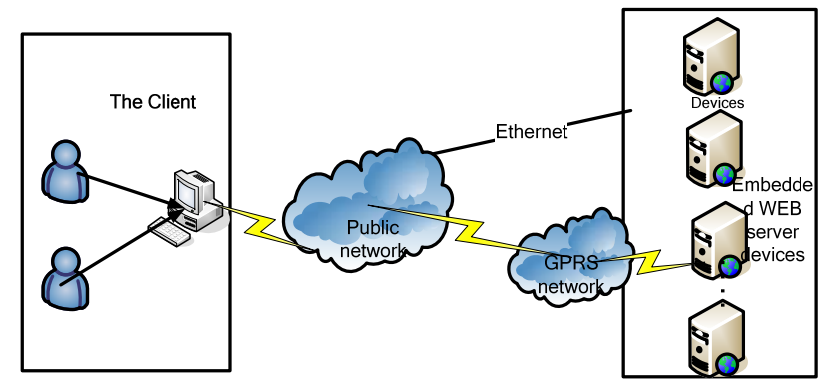

FIGURE II. THE STRUCTURE DIAGRAM OF THE EXPERIMENTAL PLATFORM 
The hardware environment configuration and specific software version used in the performance evaluation experiment of the embedded WEB server are shown in Table I.

TABLE I. HARDWARE CONFIGURATION ENVIRONMENT AND SOFTWARE VERSION OF THE EXPERIMENT PLATFORM

\begin{tabular}{|c|c|c|}
\hline Projects & Local PC & ARM Platform \\
\hline $\begin{array}{l}\text { Network } \\
\text { connection } \\
\text { mode }\end{array}$ & $\begin{array}{l}\text { Gigabit Ethernet } \\
\text { connections }\end{array}$ & $\begin{array}{lr}\text { Gigabit } & \text { Ethernet } \\
\text { interface, GPRS dial-up } \\
\text { Internet }\end{array}$ \\
\hline $\begin{array}{l}\text { Hardware } \\
\text { configuration } \\
\text { and main } \\
\text { parameters }\end{array}$ & $\begin{array}{l}\text { CPU: Pentium(R) } \\
\text { Dual-Core CPU } \\
\text { E5700 3.00GHz } \\
\text { Memory:4GB }\end{array}$ & $\begin{array}{l}\text { CPU: M6-TC1900- } \\
\text { 5001PC } \\
\text { ARM9 } 180 \mathrm{MHz} \\
\text { Memory:256MB }\end{array}$ \\
\hline $\begin{array}{l}\text { Software } \\
\text { environment } \\
\text { and version }\end{array}$ & $\begin{array}{l}\text { Operating system: } \\
\text { Microsoft } \\
\text { Windows XP } \\
\text { Professional SP3 }\end{array}$ & $\begin{array}{l}\text { Booterstrap: } \\
\text { AT91Bootstrap1.2 } \\
\text { Uboot: u-boot-1.3.4 } \\
\text { Kernel: linux-2.6.30 } \\
\text { Fs:Yaffs2 }\end{array}$ \\
\hline $\begin{array}{l}\text { Test tools and } \\
\text { WEB server } \\
\text { software } \\
\text { versions }\end{array}$ & LoadRunner8.0 & $\begin{array}{l}\text { Boa-0.94.13 } \\
\text { Httpd-2.0.64 } \\
\text { Apache-tomcat-7.0.25 } \\
\text { Ejre-1.7.0 }\end{array}$ \\
\hline
\end{tabular}

Here the embedded WEB server is already cross-compiling and transplanted to the embedded or Internet of things intelligent devices, The selected platform includes the main board platform with ARM9 as CPU processor, gigabit Ethernet interface and Linux operating system.

\section{EXPERIMENT SIMULATION AND RESULT ANALYSIS}

Because the embedded WEB server runs on the embedded intelligent product, the performance and memory size of the CPU processor of the embedded product is weaker than that of the PC machine. Therefore, in this performance evaluation, we first tested the main static characteristics of the Boa, Tomcat, Apache (HTTPD) embedded WEB server that running on the ARM9 platform and after normal operation. Table II shows the embedded WEB server that has been transplanted to the ARM9 platform will normally run its main static performance indicators in detail.

TABLE II. STATIC PERFORMANCE COMPARISON OF THE EMBEDDED WEB SERVERS

\begin{tabular}{|l|l|l|l|}
\hline \multicolumn{1}{|c|}{ Projects } & Boa Server & Apache Server & Tomcat Server \\
\hline $\begin{array}{l}\text { Space after } \\
\text { transplantation }\end{array}$ & $2.5 \mathrm{Mb}$ & $6 \mathrm{Mb}$ & $\begin{array}{l}6 \mathrm{Mb} \\
35 \mathrm{Mb} \text { JRE }\end{array}$ \\
\hline $\begin{array}{l}\text { Occupies memory } \\
\text { on running }\end{array}$ & $400 \mathrm{~Kb}$ & $2500 \mathrm{~Kb}$ & $36000 \mathrm{~Kb}$ \\
\hline $\begin{array}{l}\text { The percentage of } \\
\text { CPU used when } \\
\text { running access }\end{array}$ & $1.8 \%$ & $2.1 \%$ & $\begin{array}{l}\text { Normal running } \\
\text { access about } \\
10 \%\end{array}$ \\
\hline $\begin{array}{l}\text { Support Web page } \\
\text { language }\end{array}$ & $\begin{array}{l}\text { CGI,HTML, } \\
\text { javascript }\end{array}$ & $\begin{array}{l}\text { CGI,HTML,jav } \\
\text { ascript, } \\
\text { PHP,ASP }\end{array}$ & $\begin{array}{l}\text { HTML, } \\
\text { javascript, } \\
\text { JSP,Servlet }\end{array}$ \\
\hline $\begin{array}{l}\text { Supported } \\
\text { operating system }\end{array}$ & Unix,Linux & $\begin{array}{l}\text { Windows,Unix, } \\
\text { Linux }\end{array}$ & $\begin{array}{l}\text { Windows,Unix, } \\
\text { Linux }\end{array}$ \\
\hline Is it multi-process & $\begin{array}{l}\text { Single } \\
\text { process }\end{array}$ & $\begin{array}{l}\text { Multiple } \\
\text { processes }\end{array}$ & $\begin{array}{l}\text { Multiple } \\
\text { processes }\end{array}$ \\
\hline $\begin{array}{l}\text { Whether open } \\
\text { source }\end{array}$ & Open source & Open source & Open source \\
\hline security & weak & strong & stong \\
\hline
\end{tabular}

From the table, it can be seen that Boa server has the least amount of space, running memory, CPU and other resources. Apache (HTTPD) server is larger and the Tomcat server is the largest. However, but the security of Boa server is poor, however the security of Apache and Tomcat server is stronger.

The following are testing the dynamic performance indicators for the embedded WEB servers of Boa, Tomcat, Apache (HTTPD). Since the Boa server is a single-process server, it cannot respond in parallel, only one user request can be completed to respond to the request of another user and cannot respond concurrently. Therefore, in this test evaluation experiment, we mainly tested and evaluated the connection rate (respectively test the time required to complete the 0-2000 to connect), CPU utilization, throughput (units of time to complete the amount of data transferred on the network) and click through rate (per second user submitted to the web server to complete the number of HTTP requests).

In this experiment, the LoadRunne test software was used to conduct stress test for the embedded WEB server, tested the time required to complete $0-2000$ connections for the Boa, Tomcat, and Apache (HTTPD) servers respectively. Figure III shows the comparison of the embedded WEB server completed its corresponding connection.

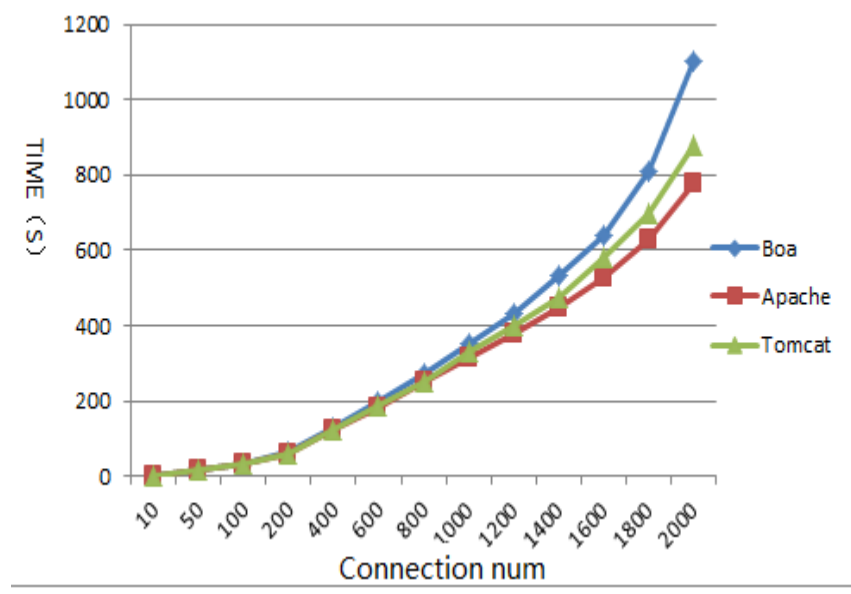

FIGURE III. THE CONNECTION RATE COMPARISON FOR WEB SERVER

In the Figure above, the horizontal coordinate is the number of connections, and the ordinate is the time it takes to complete the number of connections. As you can see in the picture when the connection number is lower, the connection rates of three kinds of the embedded WEB servers are the same basically, but when the connection number is larger, the connection rate of the three kinds of the WEB server appeared difference, especially when the connection rate is higher, the connection time of Boa server has been improved linearly.

Next, the experiment was designed to test the CPU utilization which the Boa, Tomcat, and Apache (HTTPD) servers completed the connection from 0 to 2000 respectively. Figure IV shows that the CPU utilization that the Boa, Tomcat, and Apache (HTTPD) servers completed the connection from 0 to 2000 respectively. 


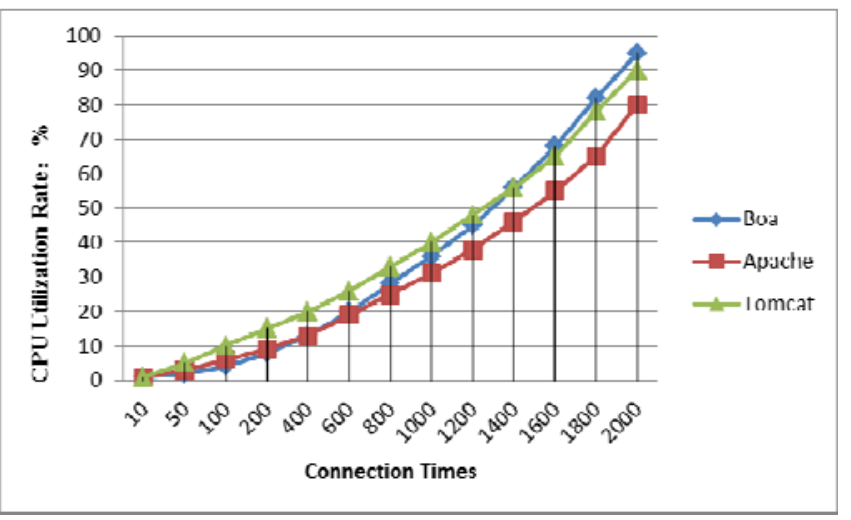

FIGURE IV. THE CPU UTILIZATION FOR WEB SERVER

From the test results in the Figure, the CPU utilization of the Boa server was lower when the number of connections less, but as the number of connections increased, the CPU utilization of the Boa server increased faster, while the CPU utilization of the Apache server increased slower. However, when the number of connections reaches a certain threshold the CPU utilization increases rapidly.

Next, we design experiment to test the throughput rate and click rate of the three kinds of WEB servers. In the experiment, a continuous connection is used to request embedded WEB server, the LoadRunne test software was used to test the throughput and click ability of embedded WEB servers within 10 minutes, then the average method is used to calculate the throughput rate and click rate. Table III shows the throughput rate and click rate of the three kinds of the embedded WEB servers.

TABLE III. COMPARE THROUGHPUT RATE AND CLICK RATE PERFORMANCE OF EMBEDDED THE WEB SERVER

\begin{tabular}{|c|c|c|c|}
\hline Test project & Boa server & $\begin{array}{l}\text { Apache } \\
\text { server }\end{array}$ & $\begin{array}{c}\text { Tomcat } \\
\text { server }\end{array}$ \\
\hline $\begin{array}{l}\text { Throughput rate } \\
\text { (throughput/test time) }\end{array}$ & 902 & $1026596 \mathrm{~Kb} / \mathrm{s}$ & $906793 \mathrm{~Kb} / \mathrm{s}$ \\
\hline $\begin{array}{lc}\text { Click rate } & \text { (click } \\
\text { num/test time) } & \\
\end{array}$ & $\begin{array}{l}8.78 \text { times } \\
\text { per second }\end{array}$ & $\begin{array}{l}9.93 \text { times per } \\
\text { second }\end{array}$ & $\begin{array}{l}8.83 \text { times per } \\
\text { second }\end{array}$ \\
\hline
\end{tabular}

In the click rate and throughput performance testing, on the platform of ARM9 processor under the condition of limited resources, the Apache server can bear the throughput and click rate of relatively good performance. But the performance evaluation and Simulation of embedded WEB server is dependent on the test platform, the performance affected by the test platform.

\section{CONCLUSIONS}

With the Internet of things products, embedded devices are increasingly applied to everyday life. The performance of embedded WEB server directly affects the intelligence and monitoring management of embedded devices. So this paper first introduces the commonly used indicators system of embedded WEB server performance evaluation: time index system, system capacity index system and resource utilization index system. Built the testing experimental platform based on ARM processor, Embedded WEB servers such as Boa, Tomcat, Apache (HTTPD) were migrated to the testing platform. The static performance and dynamic performance of the common embedded WEB server that Boa, Tomcat, Apache (HTTPD) are compared on this platform, the static performance mainly tested CPU occupancy rate, memory occupancy rate, disk occupancy rate, supported language, operating system etc, the dynamic performance mainly tests the connection rate, CPU utilization rate, throughput rate, click rate etc. The results of the experimental evaluation can provide the basis theoretical for the selection, construction and control of the embedded WEB server, it can provide a breakthrough direction to improve the response speed and stability of embedded WEB server, it can Improve the service quality of the embedded WEB server. It is of great importance to the intelligent control of embedded devices and Internet of things products.

\section{ACKNOWLEDGMENTS}

The Research was supported by The Education Department Of Hunan Province (17C1267); The Research was supported by Huaihua Science and Technology Agency Project(2017N2207); The Research was supported in part by the grants from the Huaihua University Project (HHUY201713).

\section{REFERENCES}

[1] B.Chavan; P.A.Kadam; S.R.Sawant. Embedded web server for monitoring environmental parameters[J]. Instruments and Experimental Techniques, 2009, 52(6): 784-787.

[2] Chen Xiaohui.Discussion on Web Performance testing[J]. Science and Technology Square, 2011, 23(1): 28-31.

[3] RUI Su-Juan, DING Xiao-Ming. Progress in Web Applications Performance Testing[J]. COMPUTER SCIENCE, 2006, 33(8): 278-280.

[4] Niturkar Priyanka; V.D.Shinde. Design and Development of ARM9 Based Embedded Web Server[J]. International Journal of Engineering Research and Applications, 2015, 8(5): 50-53.

[5] XU Xiang-hua, XU Ting-ting, YIN Yu-yu. Towards to Evaluating Performance of Web Server Based on Response Time[J]. Journal of Chinese Mini-Micro Computer Systems, 2013, 12(1): 90-95.

[6] Xiangyang Xu. Thr Design and Application of the Embedded Web Server[J]. Electronic Technology \& Software Engineering, 2017, 34(2): 209-212.

[7] Lin Lihua; Xie Xiufeng; Tang Shancheng; Zhao Anxin. The application and research of embedded web server technology in smart grid DTU[C]. Signal Processing, Communica- tions and Computing (ICSPCC), 2015 IEEE International Conference on, 2015.

[8] CHEN Wei, SUN Hai-yan, LI Hao-yu. Application of embedded web server in the design of ship network monitoring system[J]. SHIP SCIENCE AND TECHNOLOGY, 2017, 26(4): 172-174. 